Fixed Point Theory, 21(2020), No. 2, 739-754

DOI: $10.24193 /$ fpt-ro.2020.2.53

http://www.math.ubbcluj.ro/ nodeacj/sfptcj.html

\title{
ON BISHOP-PHELPS PARTIAL ORDER, VARIATION MAPPINGS AND CARISTI'S FIXED POINT THEOREM IN QUASI-METRIC SPACES
}

\author{
NASEER SHAHZAD* AND OSCAR VALERO** \\ * Department of Mathematics, King Abdulaziz University \\ P.O.B. 80203, Jeddah 21589, Saudi Arabia \\ E-mail: nshahzad@kau.edu.sa \\ ** Departamento de Ciencias Matemáticas e Informática \\ Universidad de las Islas Baleares \\ Ctra. de Valldemossa km. 7.5, 07122 Palma de Mallorca, Spain \\ E-mail: o.valero@uib.es
}

\begin{abstract}
In this paper we continue the study of those conditions that guarantee the existence of fixed points for variation mapping in the spirit of M.R. Tasković. Concretely, we provide a general fixed point result for variation mappings defined in left- $K$-sequentially complete $T_{1}$ quasimetric spaces in such a way that only lower semicontinuity from above is required instead of lower semicontinuity. We give examples that elucidate that the assumptions in the statement of our main result cannot be weakened. Moreover, it is shown that the $C S$-convergence condition by Tasković implies left $K$-sequentially completeness and, thus, we retrieve the fixed point result for variation mappings in $T_{1}$ quasi-metric spaces due to Tasković. Furthermore, some fixed point theorems, among other Caristi type fixed point results, for variation mappings are derived as a particular case of our main result when several different quasi-metric notions of completeness are considered. Finally, we provide a characterization of left $K$-sequentially completeness for $T_{1}$ quasi-metric spaces via variation mappings.
\end{abstract}

Key Words and Phrases: Quasi-metric, left $K$-sequentially completeness, variation mapping, Caristi mapping, fixed point.

2010 Mathematics Subject Classification: 40A05, 47H10, 54A20, 54E35, 54E50, 54H25.

Acknowledgement. The authors would like to thank the anonymous reviewer for useful comments and careful reading of the paper.

\section{REFERENCES}

[1] A. Brondsted, On a lemma of Bishop and Phleps, Pacific J. Math., 55(1974), 335-341.

[2] J. Caristi, Fixed point theorems for mappings satisfying inwardness conditions, Trans. Amer. Math. Soc., 215(1976), 241-251.

[3] Y. Chen, Y.J. Cho, L. Yang, Note on the results with lower semi-continuity, Bull. Korean Math. Soc., 39(2002), 535-541.

[4] Ş. Cobzaş, Functional Analysis in Asymmetric Normed Spaces, Birkhäuser Basel, 2013.

[5] Ş. Cobzaş, Completeness in quasi-metric spaces and Ekeland variational principle, Topology Appl., 158(2011), 1073-1084. 
[6] J. Collins, J. Zimmer, An asymmetric Arzelà-Ascoli theorem, Topology Appl., 11(2007), 23122322.

[7] B.A. Davey, H.A. Priestley, Introduction to Lattices and Order, Cambridge University Press, Cambridge, 1990.

[8] J.W. Kirk, Caristi's fixedpoint theorem and metric convexity, Colloq. Math., 36(1976), 81-86.

[9] J.W. Kirk, L.M. Saliga, The Brézis-Browder order principle and extensions of Caristi's theorem, Nonlinear Anal., 47(2001), 2765-2778.

[10] J.W. Kirk, N. Shahzad, Fixed Point Theory in Distance Spaces, Springer, 2014.

[11] H.-P.A. Künzi, A note on sequentially compact quasi-pseudometric spaces, Montsch. Math., 95(1983), 219-220.

[12] H.-P.A. Künzi, Nonsymmetric topology, in: Topology, János Bolyai Math. Studies, Budapest, 4(1995), 303-338.

[13] H.-P.A. Künzi, Nonsymmetric distances and their associated topologies: About the origins of basic ideas in the area of asymmetric topology, in: Handbook of the History of General Topology, C.E. Aull and R. Lowen (eds.), Kluwer Acad. Publ., 3(2001), 853-968.

[14] S.G. Matthews, Partial metric topology, Ann. New York Acad. Sci., 728(1994), 183-197.

[15] I.L. Reilly, P.V. Subrahmanyam, M.K. Vamanamurthy, Cauchy sequences in quasi-pseudometric spaces, Math. Slovaca, 34(1984), 299-305.

[16] S. Romaguera, E.A. Sánchez-Pérez, O. Valero, Quasi-normed monoids and quasi-metrics, Publ. Math. Debrecen, 62(2003), 53-69.

[17] S. Romaguera, P. Tirado, A characterization of Smyth complete quasi-metric spaces via Caristi's fixed point theorem, Fixed Point Theory Appl., 2015:183 (2015).

[18] M.B. Smyth, Completeness of quasi-uniform and syntopological spaces, J. London Math. Soc., 49(1994), 385-400.

[19] M.T. Tasković, Extensions of Brouwer's theorem, Math. Japonica, 36(1991), 685-693.

Received: January 31, 2018; Accepted: June 26, 2018. 